\title{
Sensitivity of Shallow Land Burial to neutron environment and activation cross sections in IFE thick-liquid concepts
}

\author{
0. Cabellos ${ }^{1,2, *}$, J. Sanz $^{1,3}$, S. Reyes ${ }^{4}$, J. Latkowski ${ }^{4}$ and N. García-Herranz ${ }^{2}$ \\ ${ }^{1}$ Institute of Nuclear Fusion, UPM, Spain \\ 2 Department of Nuclear Engineering, UPM, Spain \\ ${ }^{3}$ Department of Power Engineering, UNED, Spain \\ ${ }^{4}$ Livermore National Laboratory, LLNL, USA
}

\begin{abstract}
A comprehensive assessment on the eligibility of reduced activation (RA) steels as structural chamber material in Inertial Fusion Energy (IFE) thick-liquid concepts is performed. As far as alloying elements, it is shown that the activation of tungsten is a question to debate. Regarding impurity elements, it is analyzed if they could question the possibility of obtaining real RA steels for shallow land burial (SLB). The effect of the thickness of the liquid wall on the SLB response of alloying and impurity elements is computed. And above all, we have estimated the impact of cross section uncertainties when addressing the former questions, and we identify those to be improved. The necessary improvement of some tungsten and niobium cross sections is justified.
\end{abstract}

\section{MOTIVATION, PROBLEM DESCRIPTION AND COMPUTATIONAL METHODOLOGY}

The importance of the activation issue when selecting the chamber structural material in IFE thickliquid wall concepts has been remarked recently again [1,2]. The SLB goal, as already reported in early studies (see references in [3]), was confirmed to be very difficult to achieve, and further analysis is recognized to be needed in order to give a more definite answer. In our approach, we deal with the activation problem in a more comprehensive way, addressing some aspects not considered up to now: i) we calculate the concentration limits (CL's) corresponding to SLB for all the alloying and impurity elements that could be present in the different type of steels, and we compare those CLs with the range of chemical compositions estimated or measured for all of them; and specially ii) we estimate the effect of activation cross-section uncertainties on predicting both CL's of elements, and SLB performance of the steels. The goal is the identification of the cross sections to be improved, if necessary. In a previous study following this approach [3], extensive results have been obtained only for a single first structural wall (FSW) neutron environment representative of the HYLIFE-II reactor. Here, the sensitivity of the FSW activation to liquid wall thickness is explored, as helpful information in defining design windows. Also U and Th, the only two steel impurities not considered in [3], are here investigated.

In our analysis we have chosen the HYLIFE-II [4] thick-liquid concept. The HYLIFE-II power plant will operate at $6.4 \mathrm{~Hz}$, with a $350 \mathrm{MJ}$ yield per shot and a total fusion power of $2240 \mathrm{MW}$. An effective thickness of $60 \mathrm{~cm}$ of the molten salt flibe $\left(\mathrm{LiBeF}_{3}\right)$ between the target and structural components (steel SS304) was set to ensure a 30 full-power year lifetime for the innermost FSW segment. A flibe thickness ranging from 30 to $150 \mathrm{~cm}$ is considered here to study the variation of the FSW waste disposal rating (WDR) with liquid wall thickness. A one-dimensional spherical model is used for neutron transport and activation calculations. The neutron flux, in 566 groups, is calculated with The TART2000 code.

Details relative to the activation computational tools can be seen in [3,5]. It is worth mentioning that by using the ACAB activation code [6] we can predict the probability density function for any radiological quantity A, and consequently the relative error at any desired confidence level. Typically,

*e-mail: cabellos@din.upm.es 
that corresponding to the $95 \%$ confidence level is used $\left[\mathrm{E} 95=\left(\mathrm{A}_{95}-\mathrm{A}_{0}\right) / \mathrm{A}_{0}\right]$, where $\mathrm{A}_{95}$ is the percentile 95 of the probability distribution, and $\mathrm{A}_{0}$ the nominal value of $\mathrm{A}$ from the standard activations calculations, i.e. those using the best estimate cross sections. Here, the relative error for the $\mathrm{CL}\left(\mathrm{E}_{\mathrm{CL}, 95}\right)$ and WDR $\left(E_{W D R, 95}\right)$ quantities are the selected indexes for uncertainty estimation. In their definition, the CL95 for SLB is the concentration for which WDR $\leq 1$ with a probability of 0.95 , and the WDR95 is the $95^{\text {th }}$ percentile value of the WDR. The $\mathrm{CL}_{0}$ and the $\mathrm{WDR}_{0}$ are the conventional values computed without considering uncertainty information.

\section{WASTE MANAGEMENT ASSESSMENT AND UNCERTAINTY ANALYSIS: RESULTS AND CONCLUSIONS}

We have investigated the activation of all the alloying and impurity elements reported (see list of references in [3]) to be present in several existing 300 series stainless steels (SS304, ITER SS316 and PCA), and RA ferritic steels (FS) MagneticFE-aimed (F82H-IEA and EUROFER 97, and the ODS steel LAF-3). In Table 1 the most relevant results are presented. As far as alloying elements, those correspond to W. The presently specified W-content in intended-RAFS is ranging from 1\% (in EUROFER) to $2 \%$ (in most of the proposed RAFS). As it is seen the W performance is acceptable only for some irradiation scenarios. The CL value of $1 \%$ is obtained with a liquid thickness of $60 \mathrm{~cm}$ for 30 years of irradiation, and with 63 $\mathrm{cm}$ for 40 years. The CL of $2 \%$ is obtained with 64.5 and $67.5 \mathrm{~cm}$ for 30 and 40 years, respectively.

Table 1. CLs (wt\%) and $\mathrm{E}_{C L, 95}(\%)$ values for SLB of intended and impurity elements in present RA steels as a function of flibe thickness and irradiation time. Operating condition of $2240 \mathrm{MW}$ fusion power.

\begin{tabular}{|c|c|c|c|c|c|c|c|c|c|c|c|}
\hline \multirow[b]{3}{*}{ Ele. } & \multirow[b]{3}{*}{ Irrad. time(y) } & \multicolumn{10}{|c|}{ Flibe thickness $(\mathrm{cm})$} \\
\hline & & \multicolumn{2}{|c|}{30} & \multicolumn{2}{|c|}{60} & \multicolumn{2}{|c|}{90} & \multicolumn{2}{|c|}{120} & \multicolumn{2}{|c|}{150} \\
\hline & & $\mathrm{CL}$ & $\mathrm{E}_{\mathrm{CL}, 95}$ & $\mathrm{CL}$ & $\mathrm{E}_{\mathrm{CL}, 95}$ & CL & $\mathrm{E}_{\mathrm{CL}, 95}$ & $\mathrm{CL}$ & $\mathrm{E}_{\mathrm{CL}, 95}$ & CL & $\mathrm{E}_{\mathrm{CL}, 95}$ \\
\hline \multirow{3}{*}{ W } & 20 & $2.1 \mathrm{E}-1$ & 197.0 & $1.9 \mathrm{E}+0$ & 89.7 & ${ }^{*} \mathrm{NL}$ & 47.3 & NL & 31.0 & NL & 38.9 \\
\hline & 30 & $7.2 \mathrm{E}-1$ & 169.0 & $1.0 \mathrm{E}+0$ & 96.5 & NL & 59.4 & NL & 32.7 & NL & 39.6 \\
\hline & 40 & $2.3 \mathrm{E}+0$ & 174.0 & 7.3E-1 & 99.8 & NL & 72.3 & NL & 34.0 & NL & 40.3 \\
\hline \multirow{3}{*}{$\mathrm{Nb}$} & 20 & $1.2 \mathrm{E}-4$ & 62.5 & $7.1 \mathrm{E}-5$ & 40.5 & 3.7E-4 & 41.7 & $4.5 \mathrm{E}-3$ & 42.7 & $6.6 \mathrm{E}-2$ & 44.5 \\
\hline & 30 & $2.2 \mathrm{E}-4$ & 63.4 & $6.5 \mathrm{E}-5$ & 43.3 & $2.6 \mathrm{E}-4$ & 41.5 & $3.0 \mathrm{E}-3$ & 42.8 & 4.4E-2 & 44.5 \\
\hline & 40 & $3.3 \mathrm{E}-4$ & 39.0 & $6.7 \mathrm{E}-5$ & 46.1 & $2.0 \mathrm{E}-4$ & 41.2 & $2.2 \mathrm{E}-3$ & 42.8 & $3.3 \mathrm{E}-2$ & 44.5 \\
\hline \multirow{3}{*}{ Мo } & 20 & 8.1E-4 & 15.2 & $1.4 \mathrm{E}-3$ & 15.0 & $8.2 \mathrm{E}-3$ & 15.7 & $9.8 \mathrm{E}-2$ & 16.0 & $1.4 \mathrm{E}+0$ & 17.8 \\
\hline & 30 & $9.4 \mathrm{E}-4$ & 13.8 & $1.1 \mathrm{E}-3$ & 15.3 & $5.7 \mathrm{E}-3$ & 15.7 & $6.6 \mathrm{E}-2$ & 16.0 & $9.2 \mathrm{E}-1$ & 17.8 \\
\hline & 40 & $1.2 \mathrm{E}-3$ & 26.1 & $1.0 \mathrm{E}-3$ & 15.0 & $4.4 \mathrm{E}-3$ & 15.4 & $4.9 \mathrm{E}-2$ & 16.0 & $6.9 \mathrm{E}-1$ & 17.8 \\
\hline
\end{tabular}

${ }^{*} \mathrm{NL}=\mathrm{No}$ Limit

Regarding impurities, the only two of concern (as also found in [3]) are Mo and $\mathrm{Nb}$. The lowest value of Mo measured in F82H is 19 wppm, and a value of 5 wppm is well justified to be achievable with a relative modest effort. The CL of 19 wppm is obtained with thickness of 72 and $75 \mathrm{~cm}$ for 30 and 40 years, respectively. CLs are higher than 5 wppm for any thickness of interest. Regarding $\mathrm{Nb}$, the lowest value measured is $1 \mathrm{wppm}$, and a value of $0.5 \mathrm{wppm}$ is assumed to be achievable at present. The $1 \mathrm{wppm}$ CL is obtained with 74 and $77 \mathrm{~cm}$ of flibe for 30 and 40 years, respectively. CLs are higher than 0.5 wppm for any thickness of interest.

Regarding the impact of cross section uncertainties, it is seen that effect of cross section (XS) uncertainties induces a significant uncertainty in the SLB performance of several elements [3]. However, only the effect on $\mathrm{Nb}$ and $\mathrm{W}$ should be considered of practical significance in assessing the potential of steels as RA structural materials in thick-liquid concepts. We have identified the XS corresponding to the reactions ${ }^{94} \mathrm{Nb}(\mathrm{n}, \gamma){ }^{95} \mathrm{Nb}$ and ${ }^{192 n} \operatorname{Ir}(\mathrm{n}, \gamma){ }^{193} \mathrm{Ir}$ for the cases of $\mathrm{Nb}$ and $\mathrm{W}$ respectively, as those to be improved. For $\mathrm{Nb}$, the $\mathrm{E}_{C L, 95}$ for the thickness range of interest is around $45 \%$ and for $\mathrm{W}$ is $85 \%$. For $\mathrm{Nb}$, the CL95 of 1 wppm is obtained with 80 and $84 \mathrm{~cm}$ for 30 and 40 years, respectively. For W, the 
Table 2. $\mathrm{WDR}_{0}$ and uncertainties in WDR $\left(\mathrm{E}_{W D R, 95}\right.$ in \%) for the different steels with present impurity levels as a function of flibe thickness. Operating conditions are 30 years of irradiation time and $2240 \mathrm{MW}$ fusion.

\begin{tabular}{lcccccccccc}
\hline & \multicolumn{10}{c}{ Flibe thickness $(\mathrm{cm})$} \\
\cline { 2 - 11 } Steel & \multicolumn{2}{c}{30} & \multicolumn{2}{c}{60} & \multicolumn{2}{c}{90} & \multicolumn{2}{c}{120} & \multicolumn{2}{c}{150} \\
\cline { 2 - 11 } & WDR $_{0}$ & $\mathrm{E}_{\mathrm{WDR}, 95}$ & $\mathrm{WDR}_{0}$ & $\mathrm{E}_{\mathrm{WDR}, 95}$ & $\mathrm{WDR}_{0}$ & $\mathrm{E}_{\mathrm{WDR}, 95}$ & $\mathrm{WDR}_{0}$ & $\mathrm{E}_{\mathrm{WDR}, 95}$ & $\mathrm{WDR}_{0}$ & $\mathrm{E}_{\mathrm{WDR}, 95}$ \\
\hline EUROFER & $1.1 \mathrm{E}+1$ & 20.3 & $1.5 \mathrm{E}+1$ & 38.5 & $3.3 \mathrm{E}+0$ & 42.7 & $2.9 \mathrm{E}-1$ & 45.0 & $2.0 \mathrm{E}-2$ & 43.4 \\
F82H-IEA & $1.1 \mathrm{E}+1$ & 19.8 & $1.1 \mathrm{E}+1$ & 24.7 & $2.2 \mathrm{E}+0$ & 31.1 & $2.0 \mathrm{E}-1$ & 30.9 & $1.4 \mathrm{E}-2$ & 31.0 \\
Laf3-ODS & $5.9 \mathrm{E}+1$ & 10.7 & $4.9 \mathrm{E}+1$ & 15.9 & $9.7 \mathrm{E}+0$ & 16.7 & $8.4 \mathrm{E}-1$ & 16.7 & $5.9 \mathrm{E}-2$ & 17.8 \\
SS304 & $9.6 \mathrm{E}+0$ & 23.7 & $2.2 \mathrm{E}+1$ & 40.1 & $4.3 \mathrm{E}+0$ & 48.2 & $3.9 \mathrm{E}-1$ & 49.5 & $2.6 \mathrm{E}-2$ & 47.1 \\
\hline
\end{tabular}

CL95 of $2 \%$ is obtained with $67.5 \mathrm{~cm}(30 \mathrm{y})$ and $71 \mathrm{~cm}(40 \mathrm{y})$, and the CL95 of $1 \%$ with 65 and 67,5 $\mathrm{cm}$. Table 2 shows the SLB performance of the most promising RA steels with present impurities for thick-liquid chambers.

As concluding remarks, it seems that a reasonable liquid thickness of about $80 \mathrm{~cm}$ is allowable to obtain SLB acceptability of real RA steels. For a more definite answer, the uncertainties of some XS should be reduced. The SS304, Cr-W FS and specially ODS FS are attractive options.

\section{Acknowledgments}

Work performed under the Spain National Program on Thermonuclear Fusion, Project FTN2001-3886-C02-02, European Union keep-in-touch Program on IFE and US Department of Energy by University of California Lawrence Livermore National Laboratory under Contract W-7405-Eng-48.

\section{References}

[1] M.C. Billone, A.R. Raffray, D.K. Sze, L. El-Guebaly and the ARIES Team, IFE structural materials: ARIES assessment, University of California, San Diego, UCSD-ENG-101, December 2002.

[2] L. El-Guebaly and the ARIES Team. Fusion Science and Technology, Vol. 47, Number 3, pp. 544548, (2005).

[3] J. Sanz, O. Cabellos, S. Reyes, Effect of Activation Cross-Section Uncertainties in Selecting Steels for the HYLIFE-II Chamber to Successful Waste Management. Fusion Engineering and Design, Vol. 75-79, pp. 1157-1161, (2005).

[4] R.W. Moir, R.L. Bieri, X.M. Chen, T.J. Dolan, M.A. Hoffman, P.A. House, et al., HYLIFE-II: a molten-salt inertial energy power plant design, Fusion Technol. 25 (1994) 5.

[5] J. Sanz, R. Falquina, A. Rodríguez, O. Cabellos, S. Reyes, J.F. Latkowski, Monte Carlo uncertainty analysis of pulsed activation in the National Ignition Facility gunite shielding, Fusion Sci. Technol., 43 (2003) 473-477.

[6] J. Sanz, ACAB Activation Code for Fusion Applications: User's Manual V5.0, Lawrence Livermore National Laboratory UCRL-MA-143238, February 2000. 